\title{
Indignação e brio: o discurso sobre a improdutividade do trabalhador brasileiro na Folha de S. Paulo
}

\author{
Indignation and brio: the discourse about the unproductiveness of the Brazilian \\ worker in Folha de S. Paulo
}

\section{Indignación e brio: el discurso sobre la improductividad del trabajador brasileño en Folha de S. Paulo}

Erike Luiz Vieira Feitosa ${ }^{1}$

Angela Maria Rubel Fanini ${ }^{2}$

\begin{abstract}
Resumo
Este artigo consiste em uma análise dialógica do discurso (ADD) que se volta para a construção discursiva sobre a improdutividade do trabalhador brasileiro presente em editorial publicado pela Folha de S. Paulo no mês de abril de 2014. O texto "Brasil improdutivo" recupera enunciações da revista britânica The Economist - que, por sua vez, constrói discursivamente os brasileiros como "gloriosamente improdutivos". Obliterando vozes dissonantes, o jornal defende as premissas macroeconômicas da ideologia neoliberal e se contrapõe a medidas heterodoxas (keynesianas) que até então eram sustentadas pelos governos petistas. Posicionando-se a favor do capital, a publicação brasileira não apenas assume, mas intensifica a crítica estrangeira, reforçando a utilização do estereótipo cultural, de longa duração, que remete à imagem do brasileiro ocioso. No que diz respeito às noções de produtividade e trabalho, a análise identifica uma compreensão ideologicamente orientada para a lógica da acumulação de riquezas para poucos à custa da exploração de muitos. Quando se diz, então, que o trabalhador brasileiro ou que o Brasil é improdutivo, faz-se alusão à ideia de que ambos (país e trabalhador) deveriam produzir mais, gerar mais lucro. Tal denúncia é importante, haja vista que esses enunciados não se restringem às páginas opinativas dos jornais, mas permanecem em circulação, influenciando ideologias cristalizadas e também práticas do cotidiano, interferindo na constituição de uma consciência de si dos brasileiros, bem como na imagem que os outros (o mundo) têm deles (de nós).
\end{abstract}

Palavras-chave: Neoliberalismo e keynesianismo. Trabalhador brasileiro. Trabalhador improdutivo. Análise dialógica de discursos jornalísticos.

\begin{abstract}
This article is based on a dialogical discourse analysis that reflects about the discursive construction of the Brazilian worker present in an editorial published by Folha de S. Paulo in April 2014. The text "Brasil improdutivo" ("Unproductive Brazil") retrieves statements from the British magazine The Economist - which, in turn, constructs Brazilians discursively as "gloriously unproductive." Oblivious to dissonant voices, the newspaper defends the macroeconomic assumptions of neoliberal ideology and condemns heterodox (Keynesian) initiatives hitherto held by the PT governments. Positioning itself in favor of capital, the Brazilian publication not only assumes but intensifies the foreign criticism, reinforcing the

\footnotetext{
${ }^{1}$ Mestre em Tecnologia pela UTFPR. Jornalista do Instituto Federal do Paraná (IFPR). e-mail: erikfeitosa@gmail.com

${ }^{2}$ Doutora em Teoria da Literatura e docente da Universidade Tecnológica Federal do Paraná (UTFPR).

Programa de Pós-Graduação em Tecnologia e Sociedade (PPGTE). e-mail: rubel@utfpr.edu.br
} 
use of the cultural stereotype, of long duration, that remits to the image of the idle Brazilian. As far as the notions of productivity and work are concerned, the analysis identifies an ideologically oriented understanding of the logic of the accumulation of wealth for the few at the expense of the exploitation of many. When it is said then that the Brazilian worker or that Brazil is unproductive, it alludes to the idea that both (country and worker) should produce more, generate more profit. Such a denunciation is important, given that these statements are not restricted to the newspaper pages, but remain in circulation, influencing crystallized ideologies and also daily practices, interfering in the constitution of a self-awareness of Brazilians, as well as in the image that the others (the world) have them (of us).

Keywords: Neoliberalism and Keynesianism. Brazilian worker. Worker unproductive. Dialogical analysis of journalistic discourses.

\section{Resumen}

A través de enfoque teórico y metodológico del análisis dialógico del discurso, este artículo analiza la construcción discursiva a respecto de una suposta improductividad de los trabajadores brasileños presentes en un editorial publicado por el diario Folha de S. Paulo en abril de 2014. El texto "Brasil improdutivo" recupera enunciaciones de la revista británica The Economist - el cual, a su vez, discursivamente, retrata los brasileños como "gloriosamente improductivos". Haciendo caso omiso de las voces discrepantes, el periódico defiende los supuestos macroeconómicos de la ideología neoliberal y se opuso a las medidas heterodoxas (keynesianos) que se realizaron previamente por los gobiernos del Partido dos Trabalhadores (PT). Posicionándose a favor del capital, la publicación brasileña no sólo toma, pero intensifica la crítica extranjera, lo que refuerza el uso del estereotipo cultural, a largo plazo, que se refiere a la imagen de Brasil en reposo. Con respecto a las nociones de productividad del trabajo, el análisis identifica un posicionamento ideológicamente orientado a la comprensión de la lógica de la acumulación de riqueza para unos pocos a costa de la explotación de la mayoría. Cuando alguién dice, entonces, que el trabajador brasileño o que Brasil es improductivo se alude a la idea de que ambos deben producir más, generar más beneficios. La denuncia es importante, dado que estas declaraciones no se limitan a las páginas de los periódicos pertinaces, sino que permanecen en la circulación, que influyen en las ideologías cristalizadas y también las prácticas cotidianas, lo que interfiere con la formación de una conciencia de los brasileños, así como la imagen que el mundo tiene de nosotros.

Palabras clave: Neoliberalismo y keynesianismo. Trabajador brasileiro. Trabajador Improdutivo. Análisis dialógico de discursos periodísticos.

\section{CONSIDERAÇÕES INICIAIS}

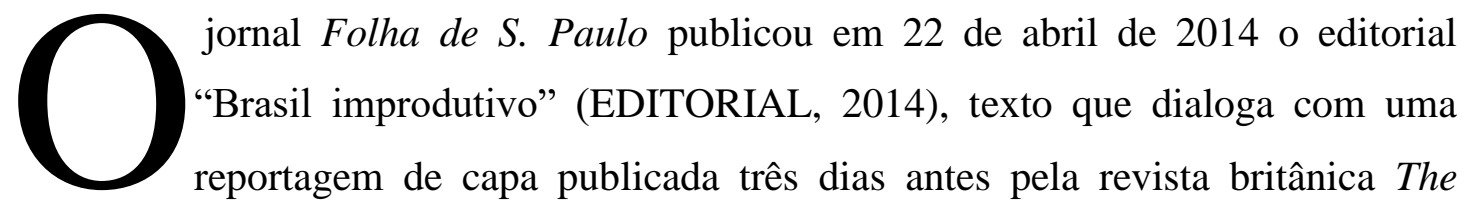


Economist $^{3}$ (THE ECONOMIST, 2014). A publicação estrangeira defende que os trabalhadores brasileiros são "gloriosamente improdutivos" e que, para a economia crescer, eles devem "acordar deste estado de estupor" (Ibid.). A centenária revista, cujos textos, por tradição editorial, não têm autoria, aconselha que o Brasil aceite uma série de medidas neoliberais no campo econômico, como, por exemplo, desregulamentações, liberalização e privatizações. Em resposta a essas recomendações, a Folha de S. Paulo não apenas concorda com a opinião estrangeira, mas a reforça e amplia, argumentando que não apenas o trabalhador, mas o país, como um todo, seria improdutivo. A forma como se constrói essa defesa, a posição a partir da qual se fala, as intenções discursivas, as vontades de verdade e de poder que amparam o discurso nos motiva a recuperar esse texto, no intuito de compreender como se estrutura a visão que o jornal, um dos mais importantes do Brasil ${ }^{4}$, faz circular sobre o trabalhador brasileiro.

Tanto o editorial quanto a reportagem estrangeira foram publicados em um momento de efervescência política no Brasil, no início de um ano eleitoral, quando o país decidiria sobre a interrupção ou continuidade do projeto neodesenvolvimentista (ALVES, 2014) capitaneado pelos governos do Partido dos Trabalhadores (PT), que havia vencido as três eleições presidenciais precedentes. Até então, a crise que afetaria o país após as eleições de 2014 era mais objeto de discursos oposicionistas do que um fenômeno verificável na realidade imediata da maioria da população. O país continuava sob o efeito positivo do crescimento econômico vivenciado na era petista e a situação ainda era a do pleno emprego (TOMAZELLI, 2014). Esse momento econômico parece ter sido fundamental para a quarta vitória consecutiva do PT nas eleições presidenciais daquele ano, apesar da forte oposição e do crescente antipetismo ${ }^{5}$, que encontrava amplos espaços de manifestação nos meios de comunicação.

O editorial veio a público nessa conjuntura - que teria influência direta no processo de impeachment de Dilma Roussef, fato histórico marcante da década ${ }^{6}$. Da mesma forma que

3 A The Economist é reconhecida internacionalmente como uma das principais defensoras do liberalismo político e econômico.

${ }^{4}$ A Folha de S. Paulo assumiu a liderança comercial entre os diários nacionais de interesse geral na década de 1980, especialmente a partir de 1984, quando passou a defender eleições diretas para presidente. De 2002 a 2013 foi o jornal de maior tiragem diária média em praticamente todos os anos, exceto em 2010 e 2011 (ASSOCIAÇÃO NACIONAL DE JORNAIS, 2016).

${ }^{5}$ Outro dado conjuntural relevante deste período foram as manifestações de junho de 2013, que inicialmente questionavam o aumento nos valores do transporte público e aos poucos foram sendo assimiladas por movimentos de direita que orientavam sua atuação a partir de discursos antipetistas.

${ }^{6}$ Não é por acaso que a agenda do novo governo se alinhou imediatamente ao pensamento neoliberal, rompendo, em todos os sentidos, com o programa eleito nas urnas. Antes disso, porém, no início do seu segundo mandato, em um aceno ao mercado, a presidente nomeou ministro da fazenda Joaquim Levy, engenheiro naval 
esse ambiente influenciou a produção desse texto, também estimulava a produção de outros conteúdos de veículos nacionais e internacionais, criando um conjunto de circunstâncias adversas ao governo e às suas ideias ${ }^{7}$. A midiatização desses embates intensificava a polarização nacional entre esquerda e direita - ainda que essa categorização não fosse precisa e coesa - e a imprensa brasileira assumia a vanguarda da oposição ao governo, geralmente pelos flancos da direita.

A Folha era um dos principais atores desses processos oposicionistas. O jornal mostrava-se conservador e seu discurso atendia aos propósitos de uma investida antigovernamental (antipetista). Por exemplo, sua avaliação sobre o índice de produtividade nacional é construída sobre a ideia de que o país não poderia avançar com o PT no poder, uma vez que o partido estimularia a improdutividade. Assim, ao defender os interesses do livre mercado em detrimento da maioria da população, seu posicionamento axiológico revela uma postura antipopular nociva aos interesses da classe trabalhadora. Assumindo essas bases ideológicas, o jornal adere aos pressupostos da ideologia neoliberal e não questiona a suposta improdutividade inerente ao brasileiro atribuída a ele pela revista estrangeira. De um lado pela militância (a favor do capital) e de outro pela omissão (na defesa do povo), acaba por fortalecer um estereótipo de longa duração que remete à imagem do nativo culturalmente ocioso. É isso o que se pretende demonstrar a seguir, a partir da perspectiva da análise dialógica do discurso (ADD).

\section{ABORDAGEM TEÓRICO-METODOLÓGICA}

O objeto de estudo de uma ADD não são os textos vistos como sistemas em si, mas os sentidos que adquirem quando são considerados seus aspectos extralinguísticos. Nessa perspectiva, não há categorias a priori, aplicáveis de forma mecânica a textos e discursos. São as relações presentes nos enunciados que possibilitam o surgimento de categorias e estratégias analíticas. A ADD lida com o embate discursivo, sem, no entanto, prometer conclusões definitivas, absolutas. Admite-se que desse confronto não surjam, necessariamente, sínteses obrigatórias, mas que a partir deles é possível observar as posições

com doutorado em economia e com posições neoliberais. Entretanto, nem isso foi suficiente para conter a crise, que se intensificava a cada dia, e evitar o cenário que possibilitou impeachment.

7 Esse cenário desfavorável ao governo é ampliado quando se leva em conta, também, as investigações e a cobertura jornalística da operação Lava Jato, que tiveram início em março de 2014 e que macularam a imagem do PT, destacadamente o associando à corrupção, ainda que, neste contexto, houvesse evidências e denúncias que abrangiam corruptos e corruptores de diferentes agremiações e matizes ideológicas. 
axiológicas dos interlocutores, os lugares ocupados pelo "eu" e pelo "outro". Não se trata de desvelar sentidos ocultos, como se houvesse algo misticamente escondido no discurso que pudesse ser vislumbrado a partir de um método já finalizado e antedado, mas de perceber as relações entre os sujeitos e os discursos em circulação e o contexto imediato e de longa duração.

O pensamento bakhtiniano tem como um de seus pilares a concepção, ampla, de diálogo. Esse diz respeito não apenas à forma clássica da comunicação verbal entre as pessoas, mas é uma metáfora ontológica da vida humana em sociedade: "Ser significa comunicar-se pelo diálogo. Quando termina o diálogo, tudo termina. Daí o diálogo, em essência, não poder nem dever terminar" (BAKHTIN, 2013, p. 293).

Para Bakhtin e o Círculo ${ }^{8}$, a linguagem é central e indissolúvel da língua, da história e da concretude da vida imediata dos sujeitos: mais do que isso, ela é situada no campo da vida. Quando o sujeito se manifesta o que ele comunica não fica restrito ao suporte material de sua comunicação, o papel, o vídeo, o áudio, o ar. Suas palavras adentram a vida imediata de outros sujeitos e podem alterá-la (refratá-la). Aí está o poder do discurso. Parafraseando Foucault (2012), filósofo da linguagem, o discurso não é pouca coisa, pois é um exercício de poder e manifesta as relações hierárquicas e as posições axiológicas dos grupos, das épocas e dos sujeitos.

A alteridade também é princípio fundante da arquitetura filosófica de Bakhtin e do Círculo. O outro pode ser tanto autor estético (e, portanto, ético) de outrem quanto personagem deste. O outro se manifesta no eu, uma vez que os enunciados, os signos e a ideologia que formam cada pessoa não lhes são exclusivos, pois foram construídos na fronteira, no diálogo, nas interconexões entre os sujeitos, relações dialógicas que estão vinculadas ao passado, interferem no presente e prenunciam o futuro. $\mathrm{O}$ eu fala e faz parte do outro e a recíproca é verdadeira.

Articulados, os princípios do dialogismo e da alteridade embasam uma rica percepção da relação social que destaca a linguagem, a comunicação ativa de um eu com um outro, e estrutura um arcabouço teórico-metodológico que extrapola os limites dos estudos linguísticos e literários, possibilitando a sua aplicação nos mais diferentes campos das Ciências Humanas, inclusive nas disciplinas ligadas ao jornalismo. Esses elementos fundantes, bem como as reflexões filosóficas que resultam de sua movimentação, sugerem aplicação direta na vida concreta dos sujeitos, realidade material e também simbólica de onde

\footnotetext{
${ }^{8}$ Bakhtin é considerado o líder intelectual de um grupo de estudiosos russos que se reunia para estudar e refletir sobre temas como linguagem e filosofia. Esse grupo ficou conhecido como o "Círculo de Bakhtin".
} 
tem origem o pensamento bakhtiniano e que também, pelo diálogo, é alterada pela ação dos sujeitos. Nesse sentido, o objetivo primário da abordagem dialógica é o embate de vozes que, anseia-se, sejam isônomas e imiscíveis. Assim, os discursos reproduzidos pelos veículos de comunicação alimentam o que a perspectiva bakhtiniana classifica como ideologia do cotidiano. São compostos por enunciados que se referem a aspectos concretos da realidade material e, por isso, criam, recriam ou distorcem essa realidade. Esses mesmos discursos podem estar ancorados em ideologias já cristalizadas, operando a partir delas ou até mesmo modificando-as, atualizando-as. Enunciações como as que serão analisadas neste artigo são, também, palavras do cotidiano, possuem articulações e origem definidas, inspiração ideológica, interlocutores reais que as promovem ou desqualificam. Elas vêm do mundo e, pelas mãos e intelecto humanos, condensam-se nas páginas do jornal, retornando à realidade imediata, refletindo-a e, ao mesmo tempo, alterando-a, desenhando ciclos dialógicos complexos e aparentemente infinitos.

\section{O “BRASIL IMPRODUTIVO”: TRABALHADOR DESCONSIDERADO}

No editorial da Folha de S. Paulo, a crítica à baixa produtividade brasileira alcança o país, como um todo, logo no título. Por mais que a discussão proposta por The Economist gire em torno do estereótipo do brasileiro preguiçoso por natureza, o jornal não faz referência, explicitamente, ao sujeito que trabalha. Aparecem apenas uma vez as expressões "trabalho" e "empregado" em uma frase do oitavo parágrafo ${ }^{9}$. Referências indiretas às provocações da The Economist dialogam com o sentimento de indignação que a reportagem provocou nos leitores brasileiros, como se percebe na abertura do editorial: "Não faltará quem se agaste, por aqui, com o tom um tanto derrisório da reportagem desta semana na revista britânica 'The

\footnotetext{
${ }^{9}$ Aqui, cabe um parêntesis. No decorrer do texto, depreende-se que o editorialista não se considera, ele mesmo, um trabalhador, como se à "classe-que-vive-do-trabalho", utilizando a expressão usada por Antunes (1999), pertencessem apenas as pessoas inseridas no contexto do trabalho material. Forma de trabalho que não está circunscrita à produção direta de valores de troca, o jornalismo, enquanto manifestação de trabalho imaterial bem como os seus jornalistas-trabalhadores, profissionais que vivem da venda de uma força de trabalho "dotada de maior dimensão intelectual" (ANTUNES, 1999, p. 125) -, está, em diversos sentidos, imbricado com a realidade do trabalho material, que, na contemporaneidade, tem assumido prioritariamente a função de gerador de valores de troca. Desse modo, não faz sentido considerar como premissa válida a clivagem entre essas duas dimensões marxianas de trabalho (material e imaterial), o que equivale a dizer que os trabalhadores de ambas as dimensões são, igualmente, trabalhadores. O que os diferencia são as formas de participação no processo de acumulação de valores de troca (acumulação de capital). Uns geram valores de troca de forma direta e os outros de maneira indireta, mas não há, em tese, diferença significativa entre eles a ponto de ser necessário considerar uns mais trabalhadores que outros - ou uma classe trabalhadora (trabalho material) e uma classe não trabalhadora (atividades imateriais, como o jornalismo). Ambas as dimensões são importantes para o capital, estão inseridas em sua lógica, contribuindo para a sua reprodução.
} 
Economist' sobre a economia do Brasil" (Ibid.). Ao dizer que a reportagem versa sobre a "economia do Brasil" e não sobre a "gloriosa improdutividade do trabalhador brasileiro" a Folha vai sem rodeios ao âmago da questão levantada pela publicação britânica. O que interessa é o diagnóstico macroeconômico, o bom funcionamento da máquina-economia: são desconsiderados os aspectos humanos que decorrem das relações sociais mediadas pelo capitalismo. Continuando a leitura do texto, vê-se, no quarto parágrafo, uma especulação a respeito da natureza do incômodo causado pela intervenção discursiva estrangeira. Para a Folha, a revista "não se limita a juízos de valor". Uma série de dados técnicos sobre a economia nacional é apresentada para comprovar essa tese, todos cunhados no âmbito da ideologia neoliberal.

\section{UNIDIMENSIONALIDADE DA MACROECONOMIA NEOLIBERAL}

A escassez de referências ao trabalhador brasileiro contrasta com o tom economicista que permeia o editorial. Há obliteração de qualquer outra dimensão da realidade objetiva e mesmo de qualquer embasamento ou discussão sobre outras perspectivas macroeconômicas que não seja a neoliberal. Compara-se o investimento brasileiro em infraestrutura com os demais países em desenvolvimento, bem como a velocidade para a emissão de patentes no Brasil com o ritmo de emissões dos Estados Unidos, Japão e China. Porém, não são considerados outros aspectos além do desenvolvimento econômico, visto apenas pela ótica desse ideário. $\mathrm{O}$ editorialista reforça a ideia de que é necessário aumentar a produtividade do trabalhador, entendida como a "chave" de todo o atraso brasileiro, mas não apresenta qualquer questionamento sobre as condições de trabalho dessas pessoas, sobre a qualidade dos empregos, a função social da atividade laborativa, o respeito aos direitos trabalhistas, entre outros sentidos que emanam do trabalho. A posição neoliberal está fechada, não dialoga com as outras, apesar de se contrapor a elas no subtexto discursivo.

Uma das principais vozes às quais o jornal se contrapõe, partindo dessa visão limitada, é a que corresponde ao pensamento keynesiano, que, à época em que o editorial foi publicado, estava associado a medidas tomadas ou incorporadas pelos governos do $\mathrm{PT}^{10}-$ ao qual, reiterando, o jornal também se opunha. Inspirado pelas ideias do economista britânico John Maynard Keynes (1883-1946), que se consolidaram principalmente a partir da

\footnotetext{
${ }^{10} \mathrm{O}$ economista Guido Mantega, ministro da Fazenda de Lula e de Dilma, intitulava-se um keynesiano, tendo adotado medidas deste ideário no período em que esteve no governo (do início de 2006 ao final de 2014).
} 
publicação do livro "A Teoria Geral do Emprego, do Juro e da Moeda" (KEYNES, 1996) ${ }^{11}$, o keynesianismo considera o Estado um agente importante para o controle da recessão econômica e do desemprego ${ }^{12}$. É uma posição, portanto, que admite a interferência estatal na economia - sem atravessar os limites da organização socioeconômica do capitalismo. Tratase de um ideário reformista, no sentido de que não está direcionado à revolução do sistema social do capital, mas à melhoria de seu funcionamento, com o consequente incremento das condições de vida no capitalismo ${ }^{13}$.

De qualquer forma, para além da centralidade da discussão econômica, vista por grande parte da imprensa como o aspecto mais relevante da vida em sociedade - sintetizada pelo senso comum de que "se a economia vai bem, tudo vai bem" -, há outras concretudes que são cruciais para a maioria das pessoas. Para os detentores da força de trabalho, não há, de forma natural, uma preocupação direta e constante sobre o desempenho das bolsas, sobre a produtividade do trabalho ou mesmo sobre o desempenho do Produto Interno Bruto (PIB). O que há são angústias sobre os reflexos da macroeconomia na vida cotidiana, como o poder de compra dos salários. A economia é um aspecto da vida material - não é "o" aspecto, como subentende o editorial. Além disso, a ideologia neoliberal fornece apenas uma maneira de se compreender as relações econômicas e sociais. Pretende-se universal, mas não é. Há outras posições ideológicas (o keynesianismo é uma delas), apesar do esforço em tentar escondê-las.

\section{DADOS INCONTESTES}

Se o texto pudesse ser dividido em partes, seriam quatro as fundamentais para se depreender a arquitetura da argumentação. A primeira delas, composta pelos seis primeiros parágrafos, diz respeito ao que o editorialista denomina de "completo atraso nacional". Após esse prólogo, apresenta-se a questão crucial, a mesma trazida pela The Economist, a "chave do atraso": a produtividade (sétimo e oitavo parágrafos). O nono parágrafo é um reflexo dessa alegada conjuntura de atraso somado à improdutividade, algo que, segundo o texto,

\footnotetext{
${ }^{11}$ Obra publicada no ano de 1936.

${ }^{12}$ De forma antagônica ao neoliberalismo, que defende um estado mínimo e não interventor.

${ }^{13}$ Tal doutrina econômica começa a tomar forma a partir de 1929, quando a economia mundial entra em uma grave crise com a quebra da Bolsa de Nova York. Keynes é um dos primeiros economistas a perceber que o livre mercado não conseguiria resolver aquele problema. Para superar a crise, o governo dos Estados Unidos colocou em prática o chamado "New Deal". O plano consistia no aumento dos gastos públicos (obras públicas que geraram milhões de empregos); controle de estoque de gêneros alimentícios (para controlar o preço e manter os empregos) e incremento nos direitos trabalhistas (fixação de salário mínimo, seguro-desemprego, entre outras medidas). Em síntese, pragmaticamente, naquele momento abandonou-se a ideia de não intervenção e o Estado americano assumiu o protagonismo das decisões macroeconômicas, o que contribui para que o país se consolidasse como a maior potência mundial do século XX.
} 
manifesta-se no baixo desempenho brasileiro no quesito exportação de mercadorias. A quarta parte fundamental é uma conclusão, que, basicamente, invoca as pessoas a transformarem o sentimento de indignação pela crítica em brio, algo que, na opinião do jornal, seria "muito mais produtivo" (EDITORIAL, 2014).

O editorial é estruturado de forma a valorizar a utilização de dados técnicos sobre a economia, informações que sempre aparecem como justificativa do quadro conjuntural que se pretende desenhar. Ressalta-se que esses índices e informações são apresentados como álibis a posições axiológicas do jornal. Não há explanações significativas sobre eles e o leitor, necessariamente, precisa recorrer a conhecimentos prévios sobre os conceitos empregados, bem como proceder a um exercício de nexo causal entre dados concretos da realidade econômica e seus efeitos na dimensão socioeconômica.

Repete o jornal que o Brasil investe só 2,2\% em infraestrutura enquanto a média do mundo em desenvolvimento é de 5,2\%. Do número de patentes concedidas pelos EUA, uma parcela ínfima é de invenções brasileiras. Também no que diz respeito à inovação, o Brasil, relata o editorial, é retardatário, haja vista que uma patente brasileira demora de cinco a dez vezes mais tempo para ser emitida do que em países como EUA, Japão e China. Todos esses fatores somados seriam responsáveis por criar um ambiente desfavorável a novos investimentos internacionais (Ibid.).

No que tange à questão da produtividade, mais uma vez a informação apresentada é resgatada do texto da The Economist. A comparação entre o produto anual do trabalho de um empregado brasileiro (US\$ 20 mil) com o mesmo índice na década de 1960 (US\$ 15 mil) e com os respectivos índices sul coreanos (menor que o do Brasil em 1960 e de quase US\$ 70 mil em 2014) e chineses é a mesma feita pela revista britânica. Isso indica concordância com a análise estrangeira. Os dados foram utilizados com os mesmos fins argumentativos - que são o de provar que o brasileiro produz pouco.

Essa posição é expressa de maneira ainda mais explícita no sétimo parágrafo: “A chave do atraso, como aponta com exatidão a revista britânica, está na produtividade”. Assim, a crítica da revista, portanto, não é apenas crível ou sensata, mas também exata, precisa e, então, não haveria motivos para questioná-la.

Com tamanho atraso, agora devidamente mapeado, e com a sua razão causal já delineada, apresenta-se um reflexo direto, mais uma vez com números aparentemente inquestionáveis, da ineficácia nacional: o país perde espaço em exportações para os chineses até mesmo na vizinha Argentina, parceira de Mercosul. 
O texto é concluído com a máxima de que a indignação nada pode contra "cifras acabrunhadoras", uma expressão muito semelhante ao dito popular que enuncia que "contra fatos não há argumentos".

A lógica, que permeia o início, o meio e o fim de toda a estrutura argumentativa, é a de que, exatos, os dados apresentados refletem uma realidade concreta, objetiva e cristalina, isenta de subjetividades e opacidades. O trabalhador brasileiro é improdutivo porque o produto anual do seu trabalho, quando comparado com o de países ricos ou com nações que também estão em vias de desenvolvimento, avança em ritmo muito menor. Perde-se tempo e dinheiro no Brasil porque "o trânsito é infernal", há muita burocracia e o custo e a qualidade dos serviços, tanto públicos quanto privados, são inadequados. Como praticamente não há inovação, também não há perspectiva de melhora na produtividade.

A utilização dos dados técnicos, algumas vezes apenas despejados no papel jornal, sem interpretação ou análise apropriada, tem, na verdade, mais a função de legitimar uma posição axiológica preliminarmente estabelecida do que, de fato, discutir as informações divulgadas ou até mesmo a tese defendida. Soltos, o leitor precisa amarrá-los com conhecimentos prévios - o interlocutor ideal é aquele que possui os mesmos signos e posições axiológicas do jornal, reforçando o já dito em atitude submissa e monológica. O editorial é redundantemente informativo e não provoca a reflexão que ocorreria se trouxesse mais dados e perspectivas menos monocausais.

\section{IMPRODUTIVIDADE COMO "ORIGEM DO ATRASO"}

Ao reforçar a ideia de que a origem de todo o atraso brasileiro surge a partir da improdutividade, o editorial incorre em reducionismo. A culpa pelo subdesenvolvimento brasileiro é jogada sobre a classe trabalhadora, sendo obliterada completamente a responsabilidade de outros grupos sociais e instituições. Também não entram nessa conta os diversos aspectos socioculturais e infraestruturais que influenciam direta ou indiretamente o panorama econômico. Não há nenhuma inferência a questões como luta de classes e má distribuição de renda, da mesma forma que não são consideradas as formas de organização política e econômica no Brasil, que, historicamente, privilegiam determinados segmentos em detrimento de outros.

Ora, se "o" problema nacional é, fundamentalmente, de produtividade, então, se de um dia para o outro, este indicador fosse equiparado ao das nações desenvolvidas ou ao dos países em desenvolvimento citados então tudo estaria resolvido. Se o produto anual do 
trabalho aumentasse, isso teria impacto positivo direto no "trânsito infernal", na "morosidade da burocracia", "no custo e na qualidade incompatíveis dos serviços públicos ou privados". Da mesma forma, se o país se tornasse mais ágil na concessão de patentes, seria automática a atração de investimentos estrangeiros.

Por trás da ideia de que as coisas no Brasil são ruins porque se trabalha pouco, há uma miríade de interesses mais vinculados ao capital que ao trabalho. $\mathrm{O}$ aumento da produtividade é ótimo para os detentores do capital, especialmente para as elites financeiras, mas não necessariamente positivo para quem vive da venda da força de trabalho. E isso é histórico. Marx (1975), ao analisar os impactos da inserção da maquinaria moderna no capitalismo industrial, constrói um relato sobre como o aumento da produtividade no sistema capitalista resulta na obtenção de mais lucros para os detentores do capital e em menor qualidade de vida para os trabalhadores. Nesse sentido, ao contrário do que se poderia imaginar, o desenvolvimento técnico (aumento da produtividade) serviu não para trazer benefícios ao trabalhador, mas para aumentar a produção do capitalista.

Tendo em vista que a natureza das relações de trabalho no sistema capitalista permanece a mesma, o relato marxiano contribui para a reflexão de que é um engodo considerar que o aumento da produtividade implicaria, de forma direta, uma superação de "todo o atraso". Pelo contrário, a história mostra que tal resultado produziria aumentos significativos de lucratividade, que não seriam, necessariamente, repassados à totalidade da sociedade. $\mathrm{O}$ avanço de poucos, nesse caso, é o atraso da maioria. Assim, nota-se o tom patronal na voz do editorial, que se manifesta em defesa de um grupo social, que não é o dos trabalhadores assalariados de quem se cobra mais trabalho.

\section{DIALETICA MONOLOGICA: IMPRODUTIVIDADE, INDIGNAÇÃO E BRIO}

O monologismo do editorial da Folha de S. Paulo se torna latente quando, após apresentar os dados supostamente inquestionáveis (décimo parágrafo), o editorialista afirma que "contra essas cifras acabrunhadoras a indignação nada pode". Em um tom sereno, quase solene, a exortação oficial do jornal é uma tentativa de abafar as vozes dissonantes. Não haveria como questionar os números, que refletiriam a realidade. Dessa forma, prossegue o texto, é “imperativo" transformar indignação em brio, este sim, um sentimento produtivo. Tal resposta ecoa como um chamado ao trabalho, mas não qualquer trabalho, e sim uma ação laborativa suficientemente produtiva. Por meio de uma enunciação floreada, o editorialista 
parece querer dizer "parem de reclamar e trabalhem" ${ }^{14}$, indicando apenas ao final da argumentação a possibilidade de ter considerado um interlocutor trabalhador (e não muito produtivo).

A palavra brio remete à noção de honra, de altivez, a uma ideia de sentimento da própria dignidade, de amor-próprio, coragem, bravura. É um vocábulo do universo moral. Uma pessoa sem brio, então, seria alguém despido de valores. Se há a necessidade de transformar indignação em brio, então são vislumbradas pelo menos duas possíveis motivações: ou o brasileiro não tem brio ou haveria nele pouco desse nobre sentimento. Uma dose extra seria necessária. É preciso que a indignação, reação equivocada, inútil, desqualificada, seja convertida em algo puro e bom: brio. Com uma única palavra, a Folha de S. Paulo cria um trabalhador brasileiro imoral, que é improdutivo por gosto, pela escolha de uma opção (o ócio) em detrimento de outra (trabalho duro, produtividade). Mais uma vez reforçando o discurso da The Economist, o editorial potencializa o estereótipo do brasileiro culturalmente preguiçoso, construção discursiva que, desde a colonização europeia do século XVI, tenta conferir ao país e ao seu povo uma identidade nacional pelo não trabalho. Nesse aspecto, ser brasileiro, então, seria ser improdutivo: "poucas culturas oferecem receita melhor para aproveitar a vida" (THE ECONOMIST, 2014).

Além disso, a palavra "imperativo" - "é imperativo transformar ócio em brio" (FOLHA DE S. PAULO, 2014) - exprime uma ordem, impõe, define algo a ser seguido, enforma uma voz voltada a dar um ponto final no diálogo. Enunciações autoritárias como essa caracterizam o que Bakhtin (2011) classifica como discurso monológico, visto como uma negação da isonomia entre as consciências em relação à verdade. Um monólogo, como este editorial da Folha de S. Paulo, é o plano de uma só consciência.

Chamamento ao "trabalho produtivo", imposição de uma versão única e fechamento para o diálogo são ingredientes que temperam o editorial. Percebidos em conjunto, apontam para uma união institucional entre veículo de comunicação e capital - ou, no mínimo, para uma conveniente coincidência axiológica no que tange às defesas macroeconômicas, o que, ao final das contas, tende a surtir os mesmos efeitos. Dessa forma, consolida-se um raciocínio aparentemente dialético que interessa somente a uma parte dos participantes do diálogo. Tratando de questões morais e de caráter, o editorial assume uma posição subjetiva, visto que não há mensuração técnica para auferir a ausência de brio. Desse modo, os dados técnicos não são chamados para a argumentação. $\mathrm{O}$ discurso preconceituoso e de longa data que desmerece

\footnotetext{
${ }^{14}$ Ironia do destino ou não, frase muito semelhante seria dita por Michel Temer em seu primeiro discurso após o impeachment: "Não fale em crise, trabalhe" (DINIZ, 2016).
} 
o brasileiro, postulando-o de preguiçoso e mau caráter, é mobilizado para a retórica discursiva. Já não é um dado técnico, mas funciona como plataforma argumentativa.

\section{PATRIOTISMO AS AVESSAS}

O editorial da Folha de S. Paulo é um reforço da crítica feita pela The Economist, uma defesa a ela ou, mais especificamente, ao que ela diz. Ao compartilharem do mesmo discurso, ambas as publicações demonstram atuar no mesmo universo ideológico, axiológico e político. De uma publicação genuinamente brasileira, o senso comum consideraria natural esperar por uma defesa dos interesses nacionais. No entanto, como foi evidenciado, não é isso que ocorre. O que há é uma blindagem discursiva, um muro construído para se interditar o debate para, aparentemente, beneficiar a tese central e a ideologia defendida pela reportagem estrangeira.

Dois rótulos operam de forma marcante neste editorial. Um é a imagem de um "Brasil improdutivo". Outro é a de um "Brasil atrasado". Enquanto produtos ideológicos, estas adjetivações adquirem significados específicos que transcendem aos sentidos que lhes poderiam ser atribuídos literalmente, refletindo e refratando uma realidade que é exterior tanto ao país em si quanto às qualidades negativas a ele atribuídas. A crítica a um Brasil que poderia estar produzindo mais corresponde aos interesses de quem poderia se beneficiar diretamente do aumento da produtividade. Sob a defesa de um Brasil mais produtivo está um anseio por um país mais lucrativo para o capital, que não necessariamente seria um país melhor para a maioria das pessoas.

Abafando outras vozes, o editorial da Folha dialoga com os argumentos da revista britânica, assumindo-os e, assim, demonstrando a posição axiológica do jornal. O texto está autorizado para ser lido como sendo a posição formalizada da empresa jornalística. Fala a todos os públicos - inclusive às pessoas assalariadas, trabalhadores de diversos ramos e setores da economia que poderiam ser enquadrados na categoria "trabalhador improdutivo" utilizada pela The Economist -, mas sua voz, tomada por um tom técnico-economicista, vai ao encontro dos interesses dos detentores do capital. E, ao fazer essa defesa, incorre em uma espécie de "patriotismo às avessas", pois, ao comparar o Brasil com outros países, vê-se obrigado a condenar o nacional e incensar o estrangeiro. Ao final e ao cabo, na defesa dos interesses do capital e movido pelo antipetismo, o texto acaba por se posicionar contra o Brasil e a favor do capital. Em síntese, é um projeto ideológico que recupera um discurso para, tão somente, reforçá-lo, enaltecê-lo. 


\section{OUTROS DADOS SOBRE O TRABALHO NO BRASIL}

A ideia de produtividade à qual The Economist (2014) e Folha de S. Paulo (2014) recorrem, bem como o estereótipo do brasileiro improdutivo resgatado por ambas, infere que o brasileiro trabalha pouco - além, é claro, de não gostar de trabalhar. Na prática, entretanto, não é isso o que demostram pesquisas sobre a realidade do trabalho no Brasil.

A começar pelo limite legal, a jornada do brasileiro é de oito horas diárias e quarenta e quatro semanais (BRASIL, 1988, art. 7), enquanto o padrão dominante mundialmente, segundo dados compilados pela Organização Internacional do Trabalho (OIT), é de 40 horas (LEE; DEIRDRE; MESSENGER, 2009, p. 20). Na prática, mais da metade da população $(52,8 \%)$ trabalha mais do que a referência legal de 44 horas. Cerca de um terço $(33,7 \%)$ têm jornada efetiva entre 44 e 48 e quase um quinto $(19,1 \%)$ enfrentam jornada superior a 48 horas semanais - apenas $23,1 \%$ mantém jornada inferior a 35 horas por semana (LEE; DEIRDRE; MESSENGER, 2009). Na média geral, de acordo com dados do IBGE, o brasileiro trabalha 40,9 horas semanais (IBGE: PNAD 2008). Esse mesmo levantamento, em consonância com os dados publicados pela OIT, demonstra que um em cada três brasileiros trabalha mais que 44 horas semanais e que um em cada cinco vai além das 48 horas por semana (Ibid).

A questão de se trabalhar muito ou pouco, entretanto, não diz respeito apenas à quantidade de horas em que a pessoa permanece no trabalho. É preciso levar em conta o tipo e a intensidade da atividade laboral. Ausentes das negociações de forma explícita, a questão do aumento da intensidade do trabalho geralmente reside nas entrelinhas dos acordos, como, por exemplo, nos relacionados aos lucros e resultados (PLR). Sabe-se que as metas de produção, produtividade ou absenteísmo "podem frequentemente levar ao aumento do ritmo de trabalho e, consequentemente, das doenças e acidentes de trabalho" (DIEESE, 2012, p. 278). Também a questão da polivalência tem sido apontada no Brasil e em outros países como de grande impacto no processo de intensificação do tempo de trabalho (DURAND, 2004; LINHART e MOUTET, 2005). Isso porque o rodízio de função leva o trabalhador a estar sempre no setor ou na função em que a demanda está mais forte, mantendo-se assim o trabalho em ritmo acelerado, com redução dos intervalos de descanso e recuperação, denominados pelo empregador como "tempos mortos" (DIEESE, 2012, p. 279). Essa intensificação, neste início de século, não está, apenas, confinada nos limites físicos do ambiente de trabalho, na fábrica, escola, escritório, empresa, repartição. Conforme pontua Pochmann (2009), especialmente no que diz respeito ao Brasil contemporâneo, muitos trabalhadores residem cada vez mais longe do seu local de trabalho, gastam verdadeiras 


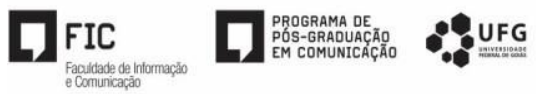

jornadas para chegar a ele, e, ainda, devido ao avanço das tecnologias da informação e comunicação (TICs) e da telefonia móvel, mesmo ausentes do ambiente laboral continuam ativos. Para piorar o quadro, as diferentes formas de trabalho imaterial não são reconhecidas, computadas ou remuneradas.

Esses dados refutam a ideia que funciona como pano de fundo da abordagem da The Economist e da Folha sobre a produtividade do brasileiro, o preconceito de que ele trabalha pouco. A maioria dos brasileiros trabalha mais e, talvez, mais intensamente, que a maioria dos trabalhadores de países desenvolvidos. Nesse sentido, fica nítido o equívoco presente na tentativa de responsabilização exclusiva da classe trabalhadora pelos maus resultados obtidos no quesito produtividade. Além do ato laborativo em si, há diversos fatores que interferem neste resultado.

Em síntese, a geração de riquezas e o aumento da produção não estão relacionados, apenas, à quantidade ou à intensidade de trabalho. Aliás, ao se pensar na riqueza, é possível afirmar que ela não possui tantas ligações diretas com o trabalho como se imagina. Para Castel (2013, p. 227), as duas categorias são completamente desconexas, pelo menos até o advento da modernidade, quando o quadro se apresenta de maneira diferente, mas resguarda certas homologias com períodos históricos precedentes. Em seu raciocínio, a riqueza é o resultado de relações desiguais, sejam elas roubos, negociações injustas, expropriações (de nações dominadas por nações dominadoras).

O trabalho não mantém uma relação visível com a riqueza e, menos ainda, a riqueza com o trabalho: via de regra, os mais ricos trabalham menos ou absolutamente não trabalham. O trabalho, ao contrário, é com frequência o quinhão dos pobres e dos que ganham pouco, reduzidos à necessidade de trabalhar a matéria ou cultivar a terra para sobreviver. É, ao mesmo tempo, uma necessidade econômica e uma obrigação moral para os que nada têm, o antídoto contra a ociosidade, o corretivo para os vícios do povo (CASTEL, 2013, p. 227).

Uma vez que o trabalho "[...] representa o meio necessário de suprir as necessidades de todos os que não são socialmente dotados" (CASTEL, 2013, p. 228), naturalizar a necessidade de se trabalhar cada vez mais, gastar mais tempo de vida para enriquecer a outros, é um comportamento que se espera do brasileiro e que interessa aos segmentos sociais mais elevados, especialmente os " $25 \%$ da população" que, neste início de século, “concentram 75\% da produção mundial" (POCHMANN, 2009, p. 17). 


\section{CONSIDERAÇÕES FINAIS}

A linguagem é um dos terrenos onde se materializam as lutas de classes. Por meio da fala, da escrita, das diferentes formas de manifestação humana, é possível avistar os posicionamentos dos sujeitos. Estes não usam a língua somente enquanto um conjunto restrito e fechado de significados, mas para se relacionar entre si de forma dinâmica no tempo e no espaço. Pensar em linguagem é também pensar em poder. Como afirma Foucault (2012), os discursos são exercícios de poder e são, também, o bem pelo qual os sujeitos lutam, ou seja, são objetos de desejo visto que aquele que fala manifesta sua diferenciação e hierarquia sobre os demais. Os meios de comunicação são importantes veículos discursivos cujos posicionamentos influenciam diretamente a sociedade. Nos meios aqui analisados, vimos a exclusão de alguns discursos mais abrangentes sobre a condição do trabalhador e a inclusão de outros, com o intuito claro de advogar pela tese da improdutividade. Nesse sentido, os enunciados transmitidos pelos veículos de comunicação se revestem de especial importância e complexidade, não apenas por representarem ou fazerem ecoar a voz das elites, mas por interferirem na materialidade da vida cotidiana, incorporando-se às vozes populares, modificando-as, ao passo em que também são modificados por elas e pelas demais enunciações interligadas pelo diálogo, seja este amistoso ou bélico.

O editorial pode ser entendido como uma porta de entrada para a compreensão das construções discursivas de um veículo de comunicação. Sendo ele o gênero relativamente estável do discurso em que são explicitadas, de forma institucionalizada, as visões do empreendimento jornalístico sobre os mais variados temas, sua leitura propicia um entendimento privilegiado das diferentes matrizes discursivas que permeiam os demais gêneros jornalísticos. Daí a sua importância estratégica para o diálogo a ser travado na leitura de qualquer jornal ou revista.

No caso em tela, ao se posicionar a favor do capital, a Folha de S. Paulo assimilou a crítica estrangeira, tornando-a positiva, orientando, a partir dela, o próprio discurso. Além disso, compartilhou com The Economist um sentido restrito de trabalhador, subentendido como um assujeitado, mera peça de uma engrenagem da qual se precisa extrair mais produção, evidenciando o tom monológico que perpassa todo o texto. Outro sentido compartilhado foi o entendimento do conceito de produtividade, que remeteu à noção, dada pelo capital, de superavit de trabalho, de acúmulo de trabalho alheio, visando à acumulação de riquezas para poucos à custa da exploração de muitos. Quando se diz, então, que o trabalhador brasileiro ou que o Brasil é improdutivo, está se fazendo alusão à ideia de que ambos (país e trabalhador) deveriam produzir mais. Em síntese, aqui, improdutivo é quem 
poderia gerar ainda mais lucro, contribuindo, assim, de forma mais efetiva para a reprodução do capital.

Em nenhum momento a utilização do coeficiente de produtividade (o PIB dividido pelo número de trabalhadores) para medir a intensidade ou a quantidade de trabalho de uma população economicamente ativa foi problematizada. Ao se analisar outros dados sobre a produtividade, percebe-se que essa fórmula está longe de oferecer uma imagem verosímil a respeito da realidade laborativa do brasileiro. Apesar de todas as camadas discursivas e culturais que pesam sobre o tema, este sujeito trabalha muito, seja em termos de jornada ou no que diz respeito à intensidade laboral - isso, sem falar na dimensão do trabalho imaterial.

O discurso sobre a improdutividade do brasileiro, tal qual ele está estruturado no editorial analisado, serve mais para militar pelos interesses do capital do que para retratar um aspecto objetivo da realidade material. Tal denúncia é importante, pois esses enunciados não se restringem às páginas do jornal, mas estão em circulação na sociedade, influenciando as ideologias cristalizadas e também as do cotidiano.

Item periférico na arquitetura discursiva, o trabalhador brasileiro é vislumbrado em dois momentos: no presente e no futuro, sendo que seu atual estágio (no ano de 2014) é muito negativo, pois este sujeito é improdutivo - e isso não se questiona, é uma pré-condição, uma característica fundante do brasileiro, a "chave do atraso do país". No entanto, no futuro, esse ser improdutivo pode, aliás, deve - e nisso consiste o autoritarismo dessa prescrição - tornarse produtivo (no sentido do termo dado pelo capital). Em outras palavras, desde que o país tenha a habilidade de construir um ambiente macroeconômico liberalizado, esse trabalhador produzirá mais, fará crescer o ritmo de acumulação do capital, o que é extremamente positivo - para o capital, e não para o trabalhador. Essa obrigação de conversão à produtividade como se o brasileiro já não estivesse trespassado por essa lógica - não é apenas uma receita para o crescimento econômico, mas é também o único caminho "correto" a ser trilhado. Ao final e ao cabo, desse embate, fica assegurada a circulação e o reforço, na ideologia do cotidiano, de um estereótipo antigo que vem a calhar aos interesses do capital: o do brasileiro culturalmente preguiçoso, improdutivo, concepção que interfere na constituição de uma consciência de si dos trabalhadores brasileiros e também na imagem que os outros (o mundo) têm deles (de nós).

Há que se considerar, entretanto, que embora represente um discurso forte, talvez até hegemônico sobre o "ser" do trabalhador brasileiro, e apesar de todo o autoritarismo contido nela, esta visão não é única. Há outros construtores da imagem externa do trabalhador, outros definidores estéticos, outras visões, por meio das quais ele também se constitui e assimila à 
sua identidade. Nesse sentido, torna-se urgente o combate à visão colonizadora e redutora desse personagem, posição que tenta relegá-lo à condição de coadjuvante na narrativa em que ele é, por direito, protagonista. É preciso evitar que se cristalize a vontade de dominação neoliberal sobre os corpos e as consciências trabalhadoras, vontade de poder que, quando hegemônica, ao recriar certa imagem do trabalhador, pode, na prática, encarcerá-lo ainda mais na lógica orientada para a unidirecionalidade do crescimento econômico por meio da exploração do trabalho alheio, antedada à revelia pelo capital. É necessário reagir, dialogicamente, contra esse discurso, a fim de preservar a construção de nossa própria identidade a partir de concepções e valores que nos interessem.

Assim, nosso posicionamento é em busca de um trabalhador que tenha condições de trabalhar, que tenha infraestrutura para trabalhar. Ele é protagonista do trabalho, e não peça problemática desse processo. Problemático é trabalhar demais, ganhar pouco e em condições sub-humanas. E é exatamente isso o que, aparentemente, o discurso neoliberal quer. Tal ideologia se restringe às dimensões meramente macroeconômicas da vida em sociedade e mesmo neste campo econômico tenta desconsiderar que, para além dela, existem outras visões possíveis. Nesta centralidade artificial, o que importa é o lucro, o superávit, e jamais a qualidade de vida da população, a qualidade do emprego, do trabalho.

Nesse aspecto, por final, cumpre ressaltar que o trabalho não é, em si, o único elemento ontológico. Há a cultura, a reflexão, o transcendente, enfim, outras dimensões humanas e, portanto, sociais, que também nos dão uma ontologia, que contornam e enformam nosso ser. Portanto, não somos e não podemos ser dados somente a partir do trabalho, e muito menos a partir do trabalho alienado, estranhado, em condições sub-humanas, como fica subentendido nos discursos inspirados pela ideologia neoliberal. Somos muito mais que isso. Assim, tanto nossa indignação quanto nosso brio precisam ser direcionados para a construção de uma sociedade em que o trabalho não seja apenas um veículo para a multiplicação do capital alheio, mas um meio para se alcançar a igualdade, a paz e a felicidade.

\section{REFERÊNCIAS}

ALVES, Giovanni. Trabalho e neodesenvolvimentismo: choque de capitalismo e nova degradação do trabalho no Brasil. Bauru (SP): Projeto Praxis Editorial, 2014.

ANTUNES, Ricardo. Os sentidos do trabalho: ensaio sobre a afirmação e a negação do trabalho. São Paulo: Boitempo Editorial, 1999. 
ASSOCIAÇÃO NACIONAL DE JORNAIS. Disponível em:

<http://www.anj.org.br/maiores-jornais-do-brasil>. Acesso em: 16 jun. 2016

BRASIL, 1988. Constituição da República Federativa do Brasil de 1988. Disponível em: <http://www.planalto.gov.br/ccivil_03/Constituicao/Constituicao.htm>. Acesso em: 21 out. 2015.

BAKHTIN, Mikhail. Estética da criação verbal. 6. ed. Tradução: Paulo Bezerra. São Paulo: Editora WMF Martins Fontes, 2011.

Problemas da poética de Dostoiévski. 5. ed. Revista. Tradução: Paulo Bezerra. Rio de Janeiro, Forense Universitária, 2013.

CASTEL, Robert. As metamorfoses da questão social: uma crônica do salário. 11. ed. Tradução: Iraci D. Poleti. Petrópolis, Editora Vozes, 2013.

DIEESE. A Situação do trabalho no Brasil na primeira década dos anos 2000.

Departamento Intersindical de Estatística e Estudos Socioeconômicos. São Paulo: DIEESE, 2012. Disponível em: <http://www.dieese.org.br/livro/2012/livroSituacaoTrabalhoBrasil.pdf> Acesso em 21 out. 2015.

DINIZ, Mariana. Temer diz que não é hora de falar em crise, mas em trabalhar. Agência Brasil, Brasília, 12 mai. 2016. Disponível em <http://agenciabrasil.ebc.com.br/politica/noticia/2016-05/temer-diz-que-nao-e-hora-de-falarem-crise-mas-em-trabalhar> Acesso em 24 set. 2018.

DURAND, J. P. La chaîne invisible: travailler aujourd'hui: flux tendu et servitude volontaire. Paris: Seuil, 2004.

EDITORIAL: Brasil improdutivo. Folha de S. Paulo, São Paulo, 22 abr. 2014. Disponível em: <http://www1.folha.uol.com.br/opiniao/2014/04/1443520-editorial-brasilimprodutivo.shtml>. Acesso em: 06 mai. 2015.

FOUCAULT, Michel. A ordem do discurso: aula inaugural no Collège de France, pronunciada em 2 de dezembro de 1970. 22.ed. São Paulo: Edições Loyola, 2012.

IBGE. Pesquisa Nacional por Amostra de Domicílios 2008. Instituto Brasileiro de Geografia e Estatística. Diretoria de Pesquisas, Coordenação de Trabalho e Rendi-mento. Rio de Janeiro, v. 29, p.1-129, 2008. Disponível em:

<http://www.ibge.gov.br/home/estatistica/populacao/trabalhoerendimento/pnad2008/brasilpn ad2008.pdf> Acesso em 22 out. 2015.

KEYNES, John Mainard. A teoria geral do emprego, do juro e da moeda. Tradução de Mário R. da Cruz. Editora São Paulo: Editora Nova Cultural Ltda., 1996.

LEE, Sangheon; DEIRDRE, McCann; MESSENGER, Jon C. Duração do trabalho em todo o mundo: Tendências de jornadas de trabalho, legislação e políticas numa perspectiva global comparada. Secretaria Internacional de Trabalho. Brasília: OIT, 2009. Disponível em:

$<$ http://www.ilo.org/wcmsp5/groups/public/---americas/---ro-lima/---ilobrasilia/documents/publication/wcms_229714.pdf> Acesso em 21 out. 2015. 
LINHART, D; MOUTET A. Le travail nous est compté: la construction des norms temporelles du travail. Paris: La Découverte, 2005.

MARX, Karl. O capital. Rio de Janeiro: Civilização Brasileira, 1975.

POCHMANN, Marcio. Qual desenvolvimento?: oportunidades e dificuldades do Brasil contemporâneo. 1. ed. São Paulo: Publisher Brasil, 2009.

THE ECONOMIST. The 50-year snooze. The Economist, São Paulo, 19 abr. 2014. Disponível em: <http://www.economist.com/news/americas/21600983-brazilian-workers-aregloriously-unproductive-economy-grow-they-must-snap-out>. Acesso em: 18 set. 2014. 